\title{
Wie Autismus das Diabetesmanagement erschweren kann
}

\author{
Der Autismus ist eine seltene Erkrankung, die für die Betroffenen vielerlei soziale Probleme \\ mit sich bringt. Wer als Hausarzt mit einem solchen Patienten konfrontiert wird, weiß um die \\ besonderen Probleme, die sich gerade beim Diabetes-Management aus dieser Störung \\ zwangsläufig ergeben.
}

_ Eine junge Ärztin beabsichtigt die Teilnahme an einer Fortbildung im Sauerland. Als sie ihre Kollegen darüber informiert, wird ihre Ortswahl mit den Worten kommentiert: Was willst Du denn da, dort werden abends doch die Bürgersteige hochgeklappt. Nach der Ankunft im Hotel verlässt sie dieses mehrmals hintereinander für kurze Zeit. Auf das merkwürdige Verhalten angesprochen, entgegnet sie: „Ich wollte nur nachsehen, ob die Bürgersteige hier wirklich hochgeklappt

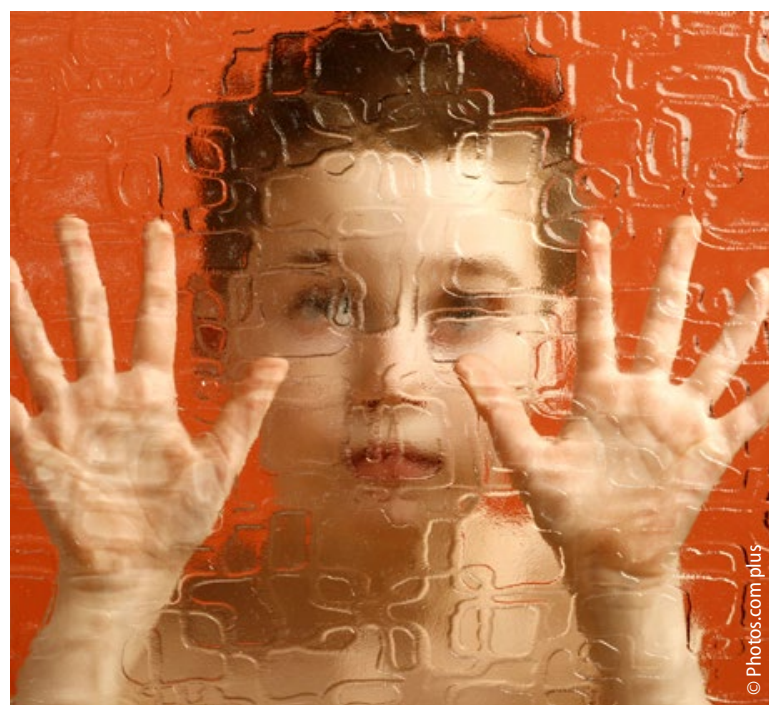
werden."

„Diese Geschichte zeigt das typische Defizit bei Menschen mit einem Autismus", so Dr. Michael Meusers von der kinder- und jugendpsychiatrischen Klinik in Herdecke. Solche Menschen zeigen nämlich ein mangelndes Symbolverständnis, aber ihre Intelligenz ist nicht beeinträchtigt. Sie leiden an einer Störung der kognitiven Empathie bzw. der sozialen Kognition. Dabei handelt es sich aber nicht um eine Persönlichkeitsstörung, wie oft fälschlicherweise angenommen wird, sondern vielmehr um eine Teilleistungsstörung des Gehirns vergleichbar mit der Legasthenie. Die Fähigkeit, sich Gefühle und Gedanken anderer vorzustellen, ist bei ihnen schon im Kindesalter gestört.

\section{Frühe Diagnosestellung lohnt sich}

Diese mit der Störung einhergehende „Loslösung von der Wirklichkeit“ äußert sich in einem Missverhältnis zwischen dem Gedanklichen und dem einfachen praktischen Tun. „Die Defizite in der verbalen und non-verbalen Kommunikation, wie sie üblicherweise zu sozialen Interaktionen genutzt wird, führen $\mathrm{zu}$ Problemen beim Beginn und der Aufrechterhaltung sozialer Beziehungen", so Meusers. Der Beginn der Erkrankung liege bereits in der frühen Kindheit. Bereits ab dem 2. Lebensjahr sei meist eine zuverlässige Diagnosestellung möglich. „Eine frühe Diagnose ermöglicht eine frühe Förderung und eine solche führt langfristig zu einem besseren Ergebnis“, so Meusers.

Doch die Langzeitprognose sei insgesamt ungünstig; denn nur jeder zweite Betroffenen kann selbständig leben und nur $10-20 \%$ finden eine reguläre Arbeitsstelle.
Vielfältige Probleme im

\section{Diabetes-Alltag}

Der Autismus ist mit einer Inzident von $1 \%$ sicherlich eine seltene Erkrankung. „Doch wenn ein Diabetologe 300 junge Diabetiker betreut, so wird er es auch mit drei autistischen Patienten zu tun haben", so Meusers. Diese seien eine besonders schwierige Herausforderung für jeden diabetologisch tätigen Arzt. Bei autistischen $\mathrm{Pa}$ tienten sei nämlich eine bildhafte Schulung kaum möglich, da kein Symbolverständnis vorhanden sei, und auch eine Erlebnispädagogik könne nicht erfolgreich sein. Der autistische Diabetiker erwarte immer "gleiche Regeln“, was aber mit der Behandlungswirklichkeit nicht vereinbar sei. Der autistische Diabetiker könne die Gedankengänge des Diabetologen nicht „mitdenken“. „Sie fragen einfach anders oder auch gar nicht", so Meusers.

Auch eine Blutentnahme wird häufig strikt abgelehnt, manchmal sogar die körperliche Untersuchung. Änderungen bei der Therapie sind nur schwer, manchmal gar nicht umsetzbar. Auch die Teilnahme an Diabeteskursen ist oft problematisch und wird abgelehnt: „Viele fremde Kinder mag ich einfach nicht.“ Das alles hat ungünstige Auswirkungen auf die Qualität der Stoffwechseleinstellung.

- Quelle: Deutscher Diabetes-Kongress am 5.5.2016 in Berlin 